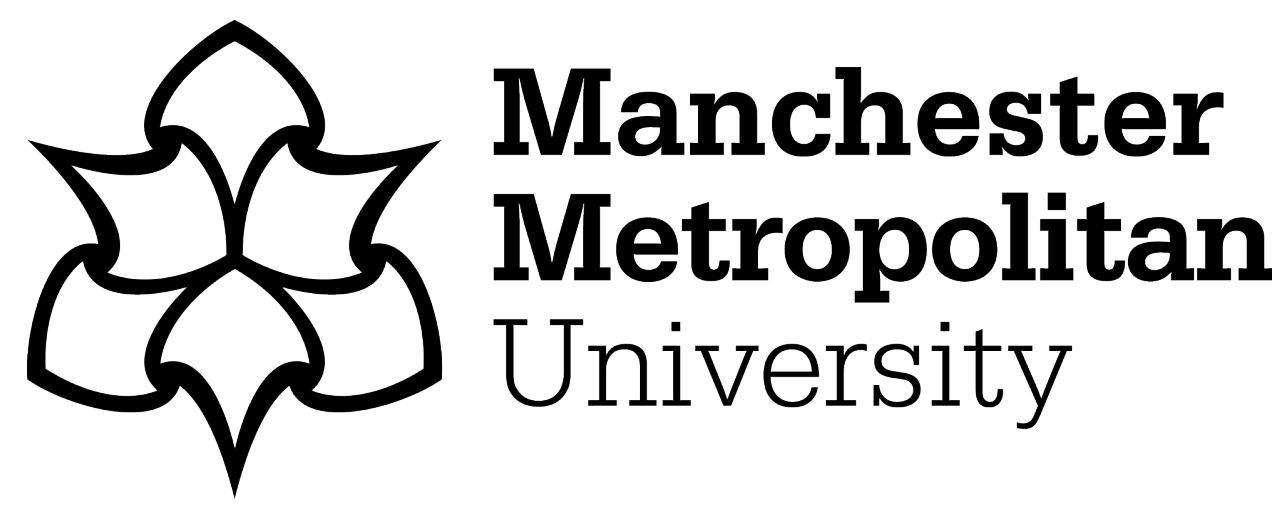

McNicol, Sarah ORCID logoORCID: https://orcid.org/0000-0001-8196-6680 (2019) Using participant-created comics as a research method. Qualitative Research Journal, 19 (3). pp. 236-247. ISSN 1443-9883

Downloaded from: https://e-space.mmu.ac.uk/622325/

Version: Accepted Version

Publisher: Emerald

DOI: https://doi.org/10.1108/QRJ-D-18-00054

Please cite the published version 


\section{Using participant-created comics as a research method}

Recent years have seen increasing interest in the use of comics and graphic novels as a means to interpret or present research (e.g. Dell'Angelo and DeGenova, 2018; Priego, 2016). However, to date, exploration of the potential of comics as method of participatory knowledge construction has been limited. In addition, the use of comics to engage communities in research, especially adult groups who may be more reluctant to participate via traditional research methods, has received relatively little attention. This article addresses these issues through a discussion of the use of comics creation as the research method adopted in a project working with a group of BritishBangladeshi women living in a town close to Manchester in the UK.

Cartoonist and comics scholar Will Eisner (1990) describes comics as a form of 'sequential art'. This description highlights two important features of comics in this context: the presence of images (usually together with written text) and the use of these images to convey a narrative. The article therefore starts by considering the use of images as a research method and the use of narrative in social research. The research discussed in this article focuses on the use of comics as a research method with participants who are often excluded from social research, commonly being described as 'hard to reach', 'vulnerable' (Ellard-Gray et al., 2015) or 'marginalized' (Gubrium and Harper, 2013), and who may not share a common language or cultural background with the research team. By describing experiences from this project in relation to the construction of images, the question of participant voice and methods of analysing the comics, the article challenges the primacy often afforded to the research interview and calls for greater openness to alternative methods of voicing participants' stories that may be better suited to the experiences and needs of such groups.

\section{The limitations of interviewing as a research method}

Probably the most commonly-used qualitative research method is the interview, but this can have significant, yet often overlooked, associations for participants. Being asked to take part in an interview may have distressing connotations as, for many participants, their previous experience of 'interviews' is likely to be in a context such as benefits review, asylum interview, interviews with social services, or at the least, job interviews - all of which can be worrying occasions. Even for those without such concerns, taking part in an interview is not necessarily a comfortable experience. For example, Slim et al. (2000: 114) argue that the interview situation tends 'to put unnatural pressure on people to find ready answers and to summarise a variety of complex experiences and intricate knowledge'. 
In addition to issues around participant expectations of an interview, there are obvious practical issues when the researcher and participants do not share a first language, including accuracy in translation of both the questions and responses, and the fact that some ideas or phrases may not be easy to directly translate. However, addressing language issues, is not simply a matter of translating the words of interviewees with limited English language skills and 'getting the meaning right' (Wheeler, 2008; Temple, 2013). Standard interview techniques may, for example, be incompatible with communal non-linear norms of communication common in different cultures, as well as failing to appreciate the importance placed on accepted storytelling norms, such as recounting a group history (Briggs, 1986; Slim et al., 2000).

Briggs (1986: 13) describes interviews as 'dialogic texts that are largely structured by the interviewer'. In an interview, attention is focused on topics introduced by the researcher's questions and the structure of the interview is usually determined by the linguistic and cultural assumptions of the interviewer, rather than those of the interviewee. As Cicourel (1986: ix) points out, 'the interview technique invariably imposes one set of communicative norms on the setting while researchers ignore the extent to which a speech community is organised along opposing lines'. This is most obviously an issue when researcher and interviewee come from different cultural backgrounds, as Briggs (1986) discusses in detail. However, even within their own culture, researchers can often 'ignore the wide range of communicative repertoires that exist' (Cicourel, 1986: ix)

\section{The use of images as elicitation}

In attempts to overcome some of the limitations of interviews described above, some researchers turn to the use of visual elicitation stimuli. Visual elicitation strategies usually involve interviews or focus groups which include the discussion of images. These images might be created by researcher or participants, or gathered from media or archives. While photographs are the most common medium used, visual elicitation can also use diagrams (Crilly et al., 2006), maps (Jung, 2014), timelines (Chen, 2018) and other techniques. Such approaches form part of a wider tradition of using creative methods, including three-dimensional media, such as Lego (Gauntlett \& Holzwarth, 2006) or games-making (Whitton, 2018). It has been argued that 'people think about things differently when making something using their hands - it leads to a deeper and more reflective engagement' Gauntlett and Holzwarth (2006: 88). Furthermore, it is claimed that the use of visual stimuli 'may yield contributions from interviewees that are difficult to achieve by verbal exchanges alone' (Crilly et al, 2006: 341), or 'evoke different kinds of knowledge from their participants than just talking would do' (Rose, 2016: 316). For example, Crilly et al. (2006: 342) discuss how 
interviewing with diagrams is considered to be particularly useful where 'cross-cultural language barriers or illiteracy limit the effectiveness of textual and verbal communication'.

While some researchers maintain they, 'do not consider visual data simply as an add-on to text based analyses' (Bagnoli, 2009: 567), it is telling that Kearney and Hyle (2004: 380) claim 'drawings are an important additional source of data' (italics added). Furthermore, Guillemin (2004: 273) believes that drawing is best used as 'an adjunct' to other social research methods and Liebenberg (2018) argues that in images 'are secondary to and supportive of the narrative' as researchers rely on some kind of spoken or written work to make the effects of the visual materials evident. There are examples of research where images have been the main focus rather than an adjunct. However, in these instances, images are often drawn in response to specific questions or prompts posed by the researcher. For example, Weber and Mitchell (1996: 17) describe how they invited informants to 'draw a teacher (any teacher)' and in research with teenage students, Gauntlett, (2005) instructed participants to asked to draw a star, celebrity or famous person who they would like to be.

\section{The importance of narrative}

While it is important to consider comics as a visual research method, that is not its only significant feature. Unlike many of the visuals used in the elicitation methods described above, comics do not simply consist of a number of discrete images; sequence or narrative is also an important component in making sense of a comic. Given that many of the most well-known, and well-loved, graphic novels are at least partially autobiographical, for example, Maus (Spiegelman, 2003) and Fun Home (Bechdel, 2006), it is perhaps surprising that there has not been greater use of comics as a research method to explore various aspects of participants' life experiences. There are theoretical arguments to explain why comics might be suited to this type of study, for example, Chute (2011: 109) describes the potential power of comics in the narration of traumatic stories where, 'Comics can express life stories, especially traumatic ones, powerfully because it makes literal the presence of the past by disrupting spatial and temporal conventions to overlay or palimpsest past and present' and argues, 'images in comics appear in fragments, just as they do in actual recollection' (Chute, 2010: 4). Ulanowicz (2011) describes how that comics can, 'make visible fragments of traumatic experience that formerly have been neglected, repressed, or censored' and El Refaie (2010: 281) claims that comics is, 'well suited to the task of conveying subjective time, since many of its formal features follow patterns that reflect the way memory itself works'. However, these principles are based on the textual analysis of published comics; the ways in which such ideas might apply with in a community-based comics creation project have not been widely explored. 
Another important factor in relation to this research is that it is often impossible to draw strict boundaries between factual and fictional accounts as memory is always incomplete and retelling involves 'selection and artful construction' (El Refaie 2008: 12). Indeed, Adams (2000: 20) describes autobiography as the 'la frontera: borderland between fiction and nonfiction', where, as El Refaie (2008: 16) argues, 'imagination may sometimes provide a more adequate expression of subjective truths than can be achieved by sticking to literal facts'. This relates to the idea, expressed by Chaney (2011: 3), that autobiographies may not be 'verifiably true', but they are generally expected to be 'emotionally truthful to the way they perceive, remember, and make sense of' an author's life. This notion of an emotional truth, which challenges 'the assumption that honesty lies in personal revelation' (Gilmore, 2001: 24), might be expressed through techniques such as fictionalising, mythologizing and the use of pseudonyms. An important consideration when working with participant-created comics, therefore is to ask whether the author is being truthful in an emotional sense, even when they are not in a verifiable one.

Whilst examples of research adopting imaginative comics creation as a method can be found in the literature, these most commonly relate to the writing up of ethnographic, or auto ethnographic, research by the researcher themselves (e.g. Dragone, 2016; Weaver-Hightower, 2012). In contrast, there is relatively limited use of participant comics creation for research, and examples which do exist mostly focus on their use with children and young people (e.g. Hughes et al., 2011; Moraveji et al, 2007). Creativity therefore often appears to be considered the preserve of the researcher, rather than the participant.

Research carried out by Sally Galman (2009) is one example of a project which did create graphic novels with adult participants, in this case pre-service teachers. In this instance, researcher and participant reviewed a transcript or tape together and participant was then asked to represent the story of their interview visually. However, as Galman (2009: 204) acknowledges, 'these are not images that the participants most likely would have created in everyday life, but were instead part of the process of reviewing their interview transcripts and retelling their stories'. That is to say, they were images drawn in response to an interview process which, as discussed above, would have been structured by the researcher.

Another example is Michael Green's (2015) research into the course he teaches on medical graphic narratives to fourth-year medical students. In this course, students critically read and discuss medically-themed comics and create their own original comic depicting a formative experience from medical school. Although the students were provided with writing prompts, and of course were 
aware the activity formed part of an assessed course, this appeared to be a more open process giving participants greater freedom to tell the stories they wished to tell.

\section{The Graphic Lives project}

The Graphic Lives project set out to explore the potential of comics-creation as a research method. Over a period of five months in spring and summer 2017, this project worked with nine women from Hyde in Greater Manchester, UK to explore their own life stories and the historical narratives of their communities. The women took part in a series of workshops including learning how to take and edit photographs using mini-tablet computers; plotting their stories using pin boards and string; reading published graphic novels on migration and related themes; and discussing extracts from oral history transcripts available in local archives. The group also visited museums and galleries to engage with collections, in particular objects from South Asia. The majority of sessions were jointly-led by a facilitator from [name of university] and a learning support worker/interpreter from [name of charity], with support from guest facilitators, for example, for the museum visits.

Following these preparatory activities, the women then used mini-tablet computers and a simple online tool called Book Creator' to create their own comic using photographs, drawings and text in any language. These comics were made available both online and as print versions. The aim of this method of comics creation was to give the women themselves opportunities to construct and tell their own stories, in their own voices and in their own ways. So, whilst some produced drawings that they then scanned and added to their comic; others searched online for stock images; and yet others made copies of their own family photographs and digitally altered them to avoid individuals being easily recognisable. In producing their final comics, most of the women used a combination of these methods. The women's comics were made available both in print and online ${ }^{\mathrm{ii}}$.

The following section considers three important aspects of the project: the construction of images; the question of participant voice; and finally, the analysis of participants' comics.

\section{The construction of images}

Researchers have reported mixed reactions to use of drawing with participants. Derry (2002) received generally positive responses to her requests to draw, which were made once interview respondents had developed a level of trust for the researcher. On the other hand, Kearney and Hyle (2004: 377), found that drawing 'could not be described as a positive factor in getting respondents to participate in the research; if anything the knowledge that they would be asked to draw may have 
deterred them from participation'. Other researchers too report that drawing exercises are unpleasant for some participants (e.g. Mannay, 2016; Richardson 2015). One issue may be the fact that drawing (and perhaps even more so, comics illustrations) are associated with children, so adults may feel awkward being asked to draw. Another consideration is lack of confidence; Rose (2016: 317) argues that participants need 'a lot of reassurance' that any kind of drawing is acceptable, whereas taking photographs is generally perceived to be easier.

In the Graphic Lives project, we chose to produce digital comics so the women were not put off by a potential lack of confidence in their drawing skills. In practice, the women were considerably more open to the idea of drawing than might have been expected based on reports from other projects. For example, it was telling that, when the women created storyboards for their comics on paper, they spontaneously chose to use images, rather than words, to convey most elements of their narratives. However, providing them with the means to use both their own photographs and stock images, in addition to drawings, gave the women further options.

It is likely that the circumstances under which participants are asked to draw can affect their willingness to do so. For example, Kearney and Hyle (2004) asked individual participants to draw whilst the researcher moved away, but remained in the interview room. It is perhaps not surprising that this may have been a deterrent for participants as they suggest; the atmosphere in the Graphic Lives workshops, where all the women were drawing together, was very different. Having the option to use photographs was also an attempt to overcome the problem of participants drawing 'what is easy to depict rather than what they might initially imagine' (Hartel et al., 2017: 435). If they wanted to include something that was difficult to draw, participants could use other types of images rather than being forced to limit their ideas to their level of drawing ability.

An issue to be considered when using participant comics creation is that it is not just the researcher who needs knowledge of visual analysis, 'participants also need to develop critical awareness of visual representations' (Gubrium and Harper, 2013: 35). We therefore included sessions within the project that would enable participants to develop their understanding of how comics work. Of course, in a short term project, it is only possible to convey a few basic ideas: the aim was not to make them expert comics creators, but to give the women sufficient skills and understanding of comics to enable them to tell their stories. Looking at published comics also gave some women more confidence in their own drawing skills as they realised that, in a comic, drawings do not have to be highly polished or detailed.

\section{Voice and representation}


As Graphic Lives participants created comics about their own stories, issues around the representation and role of participants are central to this research. However, some of the language used by other projects working with community groups appeared to jar with the ethos of Graphic Lives. For example, Gubrium and Harper (2013: 47) say, '...we tell our participants that the research process is beneficial to them because it "gives them a voice"'. The notion of 'giving voice' is not one that sits comfortably within Graphic Lives. As Janovicek (2013: 192) points out, 'Unequal power relationships cannot be addressed if researchers assume that they are the experts who give voice to the marginalised'. The participants involved in Graphic Lives clearly have their own voices and these were strongly in evidence as they developed their stories. The contribution of the project was to ensure they had control of the narrative resources (Couldry, 2010) they needed to build their accounts by helping them to develop new ways to express these stories in their own voices, using words across a number of languages, plus various types of image.

There is often a disparity evident between researchers who are keen to put their names on publications and claim credit for their work, whilst the names and faces of their participants remain hidden. As Clark (2012) comments, it is important to engage with participants 'as individuals able to enter into ethical dialogue with researchers rather than being represented merely as research subjects in need of protection'. Each woman involved in Graphic Lives was therefore given the option to use her own name in her comic or to invent a pseudonym; before they made a decision we discussed the pros and cons of each option as a group.

All the women included images of themselves (or their imaginary selves) in their comics and most included images of members of their family too. The representation of participants can be problematic in visual research. Pixilation is commonly used to provide anonymity, but this has variable results and is not always appreciated by those being protected, especially given the connections between the use of this technique in the media and ideas of criminality and victimhood (Wiles et al, 2008). In Graphic Lives, participants had a number of options to represent themselves: some drew themselves, while others used stock images of other women. However, the most common method was to use photographs of themselves and their families, but to digitally alter these using artistic filters ${ }^{\text {iii. }}$. This made it less easy to recognise individuals, but unlike pixilation, this approach gave the women themselves control over how their images were represented. Their decisions were not simply based on issues of anonymity; the choice of filter was also a creative decision based on how they wanted their story to look and how they wished to be represented.

\section{Analysis of participant comics}


Pauwels (2015: 108) refers to an 'assumption that pictures are self-evident and need no further elaboration, framing or analysis'. However, in the majority of instances, this is far from the case: images may, in fact, not be straightforward to interpret, especially for researchers more used to working with verbal interview data. Perhaps this is why visual methods tend to be used as an adjunct to the more familiar process of interviewing, as described above. In most examples of research using visual methods, 'the focus is on identifying participants' own meanings rather than interpreting drawings based on pre-existing theory' (Bagnoli, 2009: 549). Kearney and Hyle (2004: 377), for example, argue that, 'to have interpreted the drawings independent of the participants...no matter how capable the source, would likely have resulted in omissions and, perhaps, serious misinterpretations'. However, this approach is based on the assumption that there is a single 'true' version of the image to be discovered - and that this can be explained by its creator to the researcher. This emphasis on divining the meaning of images by asking the creator to explain them overlooks a crucial feature of comics: the fact that they can be read - and indeed are intended to be read - in many different ways.

The project team accompanied the women involved in the Graphic Lives project throughout the process of creating their comics and had built up relationships over a number of months. During this time, there had been many informal discussions as the comics were being created, both one-to-one as a group. At times these discussions had provoked strong, even traumatic, emotions. To ask the women to re-live these experiences once more, and particularly to record them, would not be inkeeping with the ethos and ethics of the project. Therefore, whilst discussions that took place during the creation process may inform a reading of the comics, we chose not to formally interview the women and ask them to explain their comics, but instead to analyse the comics as data in their own right.

As the women in the Graphic Lives project could include fictional or semi-fictional elements in their comics, it seemed appropriate that the analysis of their comics should instead be based on methods commonly used for the study of imaginative literary texts. In a literary context, whilst interviews with authors discussing their work may be fascinating, they are rarely used as the main means of analysing a text. As the comics were primarily creative works, it was not appropriate to treat the comics created as 'an account that can be treated like a case study' (Whitebrook, 1993: 258) depicting the lives of British-Bangladeshi women. The analysis of the comics was therefore based on an exploration of relationships between the comic, its creator (the participant) and its reader. The comic book reader has been described by McCloud (1994: 68) as the author's 'silent accomplice' and 'equal partner in crime', suggesting that comics require a substantial degree of reader participation. 
This active participation of the reader, as well as the author, in constructing meaning demonstrates Rosenblatt's (1994) transactional theory of reading, in which a literary work is conceived not as an object, but as an experience shaped by the reader, guided by clues in the text. Rosenblatt (1994: 25) proposed that a 'literary work exists in a live circuit set up between reader and text'. As a result, there is no single 'correct' or absolute meaning, but rather a series of more or less equally valid alternative interpretations. This relates to the idea of the 'rhetorical triangle' which involves examining how meaning is constructed between the arguer (or author), the argument (or text), and the audience (McNicol \& Weaver, 2013).

In the case of comics, the active role of the reader is crucial because, as Groensteen (2007: 10) describes, a comic is 'a story that is full of holes'. As a series of fragmented, static images, comics omit far more information than they include. The panels in a comic can be seen as 'visual fragments' (Groensteen, 2007: 10), often separated by empty gutters. Key to the analysis of comics, therefore, is Iser's (1989) notion of 'gaps' in the text, an absence of connections that the reader must fill in order to make sense of the text. According to Iser (1989: 169), 'The gaps function as a kind of pivot on which the whole text-reader relationship revolves'. In the case of comics, what is omitted, or left in the gutter, can be just as significant as what is included within the panels and it is the reader's interpretation of these 'gaps' which allows them to make sense of a story.

An example is Siddika's comic (figure 1). This comic is deceptively simple: whilst the language used appears straightforward at first glance, there is much that is omitted or goes unsaid, and it is left to the reader to fill in the gaps in Siddika's story. For example, she says 'I have been through many struggles, but I don't complain because the things I have been through make me stronger'. The image accompanying this text simply shows a digitally altered photograph of Siddika writing or drawing during one of the project workshops. Siddika shared some details the 'struggles' she alludes to with members of the group during one of our workshops. However, she did not wish to share these more widely and would certainly not have been comfortable discussing them in a recorded interview. Creating a comic therefore allowed her to express an emotional truth that was important to her and to voice her story, but in a way that she wanted to. The reader is given no explicit clues about what her statement might mean, although given the overarching theme of the comic, it is reasonable to imagine that Siddika's struggles are connected to relationships within her family. A reader may therefore imagine what these struggles could involve based on their own experiences of relationships or families. 
Figure 1: Page from Siddika's comic

The value of this openness in interpretation has been demonstrated when we have shared the comics with diverse audiences. For example, a reader discussing Juie's comic felt that the character was someone who felt trapped within her marriage. However, while there are 'clues' (Allen, 1998: 33) to suggest this, Juie does not use these words in her comic and based on interactions during the workshops, it feels very unlikely that she would have expressed this sentiment had we interviewed her about her comic. Experiences like this illustrate the value of exploring different interpretations of the comics, not simply those which might be shared by its creator within an interview setting.

\section{Conclusions}

The experiences of the Graphic Lives project suggest there is considerable unexplored potential for the use of comics creation as a research method when working with community groups that may be considered 'hard-to-reach'. Given the theoretical exploration of ways in which comics can communicate traumatic stories, it is perhaps surprising that there has not been greater use of this method already, but lack of confidence on part of researchers is likely to be a consideration. This relates not only to supporting participants in the creation of comics, but also to developing methods of analysis suited to this approach. Understandably, many researchers are likely to feel more confident if visual methods are supported by the more traditional and widely accepted method of interviews - a setting in which they feel more comfortable, even if their participants may not.

Whilst the problems inherent in interviewing as a research method, especially when working across different cultures, are well-known and have been debated for a number of years, the interview is still the predominant method of qualitative research. Even when visual methods are employed in an attempt to overcome some of the limitations of interviewing, in vast majority of cases these simply serve as an adjunct to the interview.

Reactions of participants in the Graphic Lives project suggest that one of the problems reported in relation to visual methods, namely participants being reluctant to draw, may not necessarily be as significant an issue as might be thought, especially in longer term projects where there is an opportunity to develop confidence and trust. Furthermore, by offering alternatives such as the use of photographs and image manipulation, participants are able to choose an option they feel most comfortable with and which they feel offers the best way to voice they own story.

A crucial difference between the comics created for the Graphic Lives project when compared to many other visual methods is that they do not seek or attempt to represent a verifiable truth. The 
project acknowledged and accepted the presence of fictional elements of autobiography and the difficulty in drawing boundaries between fiction and non-fiction. Indeed, this was seen as a strength of the stories as the use of imaginary elements offered participants a way to express emotional truths that they may otherwise have found difficult to convey.

Allowing for multiple readings of participant-created comics, rather than basing analysis on the meaning described by the participant-creators, may be perceived as problematic given what Watson (2011: 406) describes as 'the inherent tendency of research to impose closure' and the common expectation that 'interpretation has to come from the person that made the artefact' (Gauntlett and Holzwarth, 2006: 89). However, it is important to consider that, whilst interviewing participants could be one way to analyse participant-created comics in certain circumstances, this should not simply be the default. In the Graphic Lives project, it was important to accept that participants had already voiced their story in a certain way - using words and images - during the creative process. The project needed to accept and respect their voices as they had chosen to present them and not expect the participants to transform this into something that was more aligned with what the researcher might want to hear.

The nature of comics as a series of fragmented images that require the active involvement of the reader to make sense of the story means that expecting to discover a single 'true' explanation of meaning (usually the participant's/creator's explanation) is not possible. In addition to treating participant-created comics as sources of data in their own right, and not as secondary to an interview, it is important that comics are not simply analysed as case studies of particular communities. Rather, as imaginative, creative works, comics highlight the value of allowing for multiple interpretations. Failure to explore different interpretations and choosing to base an analysis solely on the explanations participants are comfortable voicing in an interview may seriously limit the potential understanding that can be gained from participant-created comics. Rather, exploring the relationships between comic, author and reader may lead to new kinds of knowledge about the experiences of communities that are often overlooked by more traditional methods.

\section{References}

Adams, TD (2000) 'Heightened by life' vs. 'Paralyzed by fact': Photography and autobiography in Norma Cantú's Canícula. Biography 24(1): 57-71.

Allen, C (1988) Louise Rosenblatt and theories of reader-response. Reader 20: 32-9.

Bagnoli, A (2009) Beyond the standard interview: The use of graphic elicitation and arts-based methods. Qualitative Research 9(5): 547-70.

Bechdel, A (2006) Fun Home. London: Jonathan Cape 
Briggs, CL (1986) Learning How to Ask. Cambridge: Cambridge University Press.

Chaney, MA (2011) Introduction, in M.A. Chaney (Ed.) Graphic Subjects: critical essays on autobiography and graphic novels. Madison: The University of Wisconsin Press.

Chen, AT (2018) Timeline drawing and the online scrapbook: Two visual elicitation techniques for a richer exploration of illness journeys. International Journal of Qualitative Methods, https://doi.org/10.1177/1609406917753207

Chute, H (2011) Comics form and narrative lives. Profession 2011: 107-117.

Chute, H (2010) Graphic Women: Life narrative and contemporary comics. New York: Columbia University Press.

Cicourel, AV (1986) Foreword in CL Briggs (author) Learning How to Ask. Cambridge: Cambridge University Press, ix-xii.

Clark, A (2012) Visual ethics in a contemporary landscape. Pink, S (ed) In Advances in Visual Methodology. London: Sage, 17-35

Couldry, N (2010) Why Voice Matters: Culture and politics after neoliberalism. London: Sage.

Crilly, N, Blackwell, AF, Clarkson, PJ (2006) Graphic elicitation: Using research diagrams as interview stimuli. Qualitative Research 6(3): 341-66.

Dell'Angelo, T, DeGenova, M, (2018) "I am a teacher": Early career teachers in high needs schools. The Comics Grid: Journal of Comics Scholarship 8: 5.

Derry, C (2002) More than Words Can Say? The Value of Drawings in Qualitative Research, Paper presented as part of the symposium, Using Visual Images in Research: Methodological Issues and Innovations, at the annual meeting of the American Educational Research Association, New Orleans, LA, April.

Dragone, F (2016) The making of Lissa: Still Time - An ethnographic novel. Teaching Culture, http://www.utpteachingculture.com/the-making-of-lissa-still-time-an-ethnographic-novel/

Eisner, W (1990) Comics and Sequential Art. Tamarac, FL: Poorhouse Press.

El Refaie, E (2010) Subjective time in David B's graphic memoir 'Epileptic'. Studies in Comics 1(2): 281-299.

El Refaie, E (2008) Autobiographical Comics: life writing in pictures. Jackson, MS: University Press of Mississippi.

Ellard-Gray, A, Jeffrey, NA, Melisa Choubak, M, Crann, SE (2015) Finding the hidden participant: Solutions for recruiting hidden, hard-to-reach, and vulnerable populations. International Journal of Qualitative Methods, https://doi.org/10.1177/1609406915621420

Galman, SAC (2015) The truthful messenger: Visual methods and representation in qualitative research in education. Qualitative Research 9(2): 197-217. 
Gauntlett, D. (2005) Using creative visual research methods to understand media audiences. MedienPadagogik, 4(1), http://www.medienpaed.com/04-1/gauntlett04-1.pdf .

Gauntlett, D, Holzwarth, P (2006) Creative and visual methods for exploring identities. Visual Studies 21(1): 82-91.

Gilmore, L (2001) The Limits Of Autobiography: Trauma and testimony. Ithaca: Cornell UP.

Green, M (2015) Comics and medicine: Peering Into the process of professional identity formation. Academic Medicine 90(6): 774-9.

Groensteen, T (2007) The System of Comics. Jackson: University Press of Mississippi.

Gubrium, A, Harper, K (2013) Participatory Visual and Digital Methods. Walnut Creek CA: Left Coast Press.

Guillemin, M (2004) Understanding illness: using drawings as a research method. Qualitative Health Research 14(2):272-89

Hartel, J, Noone, R, Oh, C, Power, S, Danzanov, P, Kelly, B (2017) The iSquare protocol: Combining research, art, and pedagogy through the draw-and-write technique. Qualitative Research 18(4): 43350.

Hughes, JM, King, A, Perkins, P, Fuke, V (2011) Adolescents and "Autographics": Reading and writing coming-of-age graphic novels. Journal of Adolescent \& Adult Literacy 54(8): 601-12.

Iser, W (1989) Prospecting: from reader response to literary anthropology. Baltimore: John Hopkins University Press.

Janovicek (2013) 'If you'd told me you wanted to talk about the '60s, I wouldn't have called you back': Reflections on collective memory and the practice of oral history. In Sheftel, S. Zembrzycki (eds) Oral History Off the Record: Toward an ethnography of practice. New York: Palgrave Macmillan: 185-200.

Jung, $H$ (2014) Let their voices be seen: Exploring mental mapping as a feminist visual methodology for the study of migrant women. International Journal of Urban and Regional Research 38(3): 9851002.

Kearney, KS, Hyle, AE (2004) Drawing out emotions: The use of participant-produced drawings in qualitative inquiry, Qualitative Research 4(3): 361-82.

Liebenberg, L (2018) Thinking critically about photovoice: Achieving empowerment and social change. International Journal of Qualitative Methods, https://doi.org/10.1177/1609406918757631. Mannay, D (2016) Visual, Narrative and Creative Research Methods: Application, Reflection and Ethics. Abingdon: Routledge.

McCloud, S (1994) Understanding Comics: the invisible art. New York: Harper Collins. 
McNicol, S and Weaver, S (2013) "'Dude! You mean you've never eaten a peanut butter and jelly sandwich?!?' Nut Allergy as Stigma in Comic Books". Health Communication, 28(3): 217-25.

Moraveji, N, Li, J, Ding, J, O'Kelley, P, Wolfe, S (2007) Comicboarding: using comics as proxies for participatory design with children. In Proceedings of the SIGCHI conference on Human Factors in Computing Systems (pp.1371-1374). San Jose, USA: ACM Press.

Pauwels, L (2015) 'Participatory' visual research revisited: A critical-constructive assessment of epistemological, methodological and social activist tenets. Ethnography 16(1): 95-117.

Priego, E. (2016) Comics as research, comics for impact: The case of higher fees, higher debts. The Comics Grid: Journal of Comics Scholarship 6: 16.

Richardson, MJ (2015) Embodied Intergenerationality: Family Position, Place and Masculinity. Gender, Place \& Culture: A Journal of Feminist Geography 22 (2): 157-71.

Rose, G (2016) Visual Methodologies: An introduction to researching with visual methods (4th ed). London: Sage.

Rosenblatt, LM (1994) The Reader, the text, the poem: The transactional theory of the literary work. Carbondale, IL: Southern Illinois University Press.

Slim, H, Thompson, P, Bennett, O, Cross, N (2000) Ways of listening in R. Perks and A. Thomson (eds), The Oral History Reader, 114-125. London: Routledge.

Speigelman, A (2003) The Complete MAUS. London: Penguin.

Temple, B (2013) Casting a wider net: Reflecting on translation in oral history. Oral History 41(2): 101-109.

Ulanowicz, A (2011) Review of 'Graphic Women: Life narrative and contemporary comics', ImageText 5(4), http://www.english.ufl.edu/imagetext/archives/v5 4/ulanowicz/.

Watson, C. (2011) Staking a small claim for fictional narratives in social and educational research. Qualitative Research 11(4): 395-408.

Weaver-Hightower, MB (2012) Waltzing Matilda: An autoethnography of a father's still birth. Journal of Contemporary Ethnography 41: 462-91.

Weber, S and Mitchell, C (1996) Drawing ourselves into teaching: Studying the images that shape and distort teacher education. Teaching and Teacher Education 12(3): 301-13.

Wheeler, N (2008) Cross-lingual oral history interviewing in China: Confronting the methodological challenges. Oral History 36(1): 56-68.

Whitebrook, M (1993) Only connect: Politics and literature 10 years later. Political Science and Politics 26(2): 257-62.

Whitton, NJ (2018) Playful learning: Tools, techniques, and tactics. Research in Learning Technology. 26: 1-12. 
Wiles, R, Prosser, J, Bagnoli, A, Clark, A, Davie, K, Holland, S, Renold, E (2008) Visual ethics: Ethical issues in visual research. ESRC National Centre for Research Methods Review Paper, NCRM/011.

' https://bookcreator.com/

ii url to be added

iii https://www298.lunapic.com/editor/ 